\title{
Artificial Ribozyme-Based Regulators of Gene Expression
}

\author{
Isabelle T. Seemann, Jörg S. Hartig* \\ Department of Chemistry and Konstanz Research School Chemical Biology (KoRS-CB), University of Konstanz, \\ 78457 Konstanz, Germany \\ Fax+49(7531)885140; E-mail: joerg.hartig@uni-konstanz.de
}

\begin{abstract}
The development of RNA-based switches of gene expression is summarized. Most switches are based on the Schistosoma mansonii hammerhead ribozyme (HHR), a self-cleaving RNA sequence that is inserted into an mRNA. Control of HHR self-cleavage is achieved by the attachment of an aptamer domain to the HHR scaffold. External addition of a small-molecule ligand regulates catalytic activity of the ribozyme and hence gene expression. These socalled aptazymes are suited to control several classes of RNA. In addition to mRNA, we have incorporated artificial RNA switches into tRNA as well as the bacterial 16S rRNA. In addition, the presented switches should be widely applicable as demonstrated by experiments in bacteria, yeast, and mammals.
\end{abstract}

\author{
1 Introduction \\ 2 Ribozymes in Nature \\ 3 Ribozymes as Parts for Artificial mRNA Switches \\ 4 Regulation of Further RNA Classes \\ 5 Conclusion
}

Key words: ribonucleic acid, aptamer, riboswitch, hammerhead, RNA-ligand interaction

\section{Introduction}

Ribonucleic acids (RNA) are important intermediates in gene expression. The major classes messenger RNA (mRNA), transfer RNA (tRNA) and ribosomal RNA (rRNA) play fundamental roles in the transmission of information from DNA to protein. The expression of individual genes is highly regulated. Conditional gene expression in bacteria is dominated by proteins such as transcription factors. Indeed the majority of genes is regulated by protein-based mechanisms, but the discovery of riboswitches by Breaker and co-workers demonstrated a pivotal role of RNA in bacterial gene regulation. ${ }^{1}$

In contrast to protein-based regulation systems, riboswitches do not require protein factors for the regulation of gene expression. Usually riboswitches are intramolecular (or cis-acting) RNA motifs which are embedded in the $5^{\prime}$-untranslated region (5'-UTR) of mRNA. They consist of two main domains: an aptamer domain, which can specifically bind a metabolite and thereby sense a chemical stimulus. This signal is then communicated to the second domain, a so-called expression platform that changes gene expression by affecting transcription elongation, translation initiation, or mRNA stability. The process of 'communicating' the presence of an interaction partner from one domain to another is usually facilitated by re-folding of respective RNA elements in order to adopt alternate structures and hence functions. Many different naturally occurring riboswitches have been reported. ${ }^{2}$ Interestingly, similar but artificial systems had been constructed by some researchers several years before natural systems were discovered. ${ }^{3}$ These artificial, RNA-based regulators were developed by using in vitro selected aptamer motifs. Aptamers are binders composed of short nucleic acids which specifically recognize interaction partners. They can be obtained through a combinatorial in vitro selection process, called systematic evolution of ligands by exponential enrichment (SELEX). ${ }^{4}$

In recent years artificial riboswitches responding to novel ligands in both bacteria and in eukaryotes have been constructed. For this purpose, a gene-regulatory element is inserted into an mRNA. This is carried out on the DNA level by techniques for manipulating genetic information, and then this information is introduced into the respective cells. Next, the gene switch is transcribed and can be triggered by a chemical stimulus. ${ }^{5}$ In addition to inserting ligand-sensing modules into mRNA, the incorporation of catalytically active elements such as the hammerhead ribozyme (HHR) as expression platform enlarged the diversity of artificial RNA-based switches and their mechanisms to regulate gene expression. In this case ligand binding to the aptamer domain triggers changes in the kinetics of a phosphodiester-cleaving ribozyme, which influences gene expression, for example, via the liberation of the ribosome binding site in Escherichia coli (E. coli) ${ }^{6}$ This connection of an aptamer and a ribozyme is called an aptazyme. We and others have shown that the ligand-controlled, ribozyme-mediated cleavage reactions can be used for the regulation of different RNA classes and their functions, such as mRNA, tRNA, rRNA and microRNA. In this Account we give an overview of different concepts used to regulate gene expression via ribozyme-based RNA switches, controlled by small-molecule ligands.

\section{Ribozymes in Nature}

RNA motifs that can catalyze reactions are called ribozymes in analogy to enzymes. Naturally occurring ribozymes such as $\mathrm{RNase}^{7}$ or self-splicing ribozymes ${ }^{8}$ have been discovered in the early 1980s. In 2000 it be- 
came evident that even the ribosome is a ribozyme, as it catalyzes the peptidyltransferase reaction via RNA residues. ${ }^{9}$ In the gImS riboswitch, a ribozyme serves as a regulatory element by ligand-induced cleavage of the mRNA resulting in inhibition of gene expression. Upon binding of its metabolite glucosamine-6-phosphate an autocatalytic cleavage of the gImS mRNA is triggered, resulting in mRNA degradation via a specific nuclease and reduced gene expression. ${ }^{10}$ Recently a novel regulatory riboswitch containing a group I intron ribozyme has been described by Breaker and co-workers. ${ }^{1}$. This c-di-GMP-binding motif found in eubacteria is capable of controlling termination of transcription. Group I introns catalyze self-splicing reactions, in which guanosine is bound and performs a nucleophilic attack on the $5^{\prime}$-splice site. Subsequently, a conformational change induces a second cleavage reaction at the $3^{\prime}$-splice site resulting in exon ligation and intron release. ${ }^{12}$ In this case upstream of the intron a c-diGMP-binding aptamer was found, controlling the initial, ribozyme-mediated attack of the guanosine in a ligand-dependent way. In the absence of c-di-GMP splicing and translation do not take place, whereas in the presence of cdi-GMP splicing occurs and gene expression can proceed. " A similar but artificial system has been realized by Ellington and co-workers. By appending a theophylline aptamer to the group I intron ribozyme, they were able to generate a group I aptazyme whose in vivo splicing is mediated by externally added theophylline. ${ }^{13}$

For constructing artificial, RNA-based switches of gene expression we utilized the hammerhead ribozyme (HHR). The reaction catalyzed by this catalytically active RNA is described by a phosphodiester reaction where a 2 '-hydroxyl group attacks the phosphodiester, generating a $2^{\prime}$ 3 -pentacyclic phosphodiester and a free 5'-hydroxyl group, resulting in RNA strand cleavage (see Scheme 1, A) ${ }^{14}$ This cleavage mechanism is also performed by the HHR identified in Schistosoma mansonii, ${ }^{15}$ the probably best characterized and most frequently used ribozyme sequence in synthetic applications. The HHR is a small RNA motif that was originally discovered in viroids, but now has been found in several eukaryotic genomes. ${ }^{16} \mathrm{It}$ comprises three helical arms (stems I-III), flanking a conserved catalytic core. The catalysis is dependent on divalent metal ions such as magnesium. It has been shown that tertiary interactions between stems I and II stabilize the catalytically active conformation. ${ }^{17}$ The minimal ribozyme motif lacks those tertiary interactions and requires higher magnesium concentrations for efficient ribozyme cleavage. The interaction of stems I and II distant to the active site enable the formation of an in-line geometry for the nucleophilic attack, locking the ribozyme in a catalytic active conformation. ${ }^{17 c, 18}$

The discovery of ribozymes in nature inspired many researchers to generate artificial ribozymes with novel activities. A motivating aspect was the RNA world hypothesis, suggesting that early life developed based on RNA as the sole biopolymer. ${ }^{19}$ Hence catalytic RNA rather than protein-based enzymes would have been responsible for catalyzing the first metabolic reactions. Synthetic ribozymes catalyzing key metabolic and genetic tasks, such as RNA polymerase activity, ${ }^{20}$ peptidyl-transfer reactions, ${ }^{21}$ or aminoacyl-transfers ${ }^{22}$ have been discovered by in vitro selection protocols. In addition, further activities such as hydroxyl-phosphorylation reactions ${ }^{23}$ or the enantioselective carbon-carbon bond formation by the Diels-Alder reaction can be catalyzed efficiently by in vitro selected ribozymes. ${ }^{24}$

\section{Biographical Sketches}

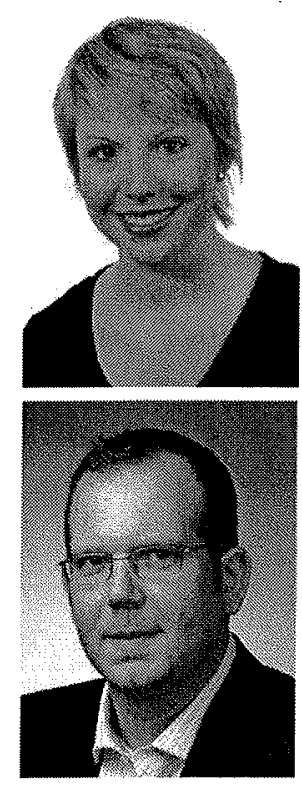

Isabelle Seemann was born in Tuttlingen, Germany, in June of 1986. She obtained her BSc in Life Science from the University of Kon$\operatorname{stan} z$ in 2008 . Later, she obtained her master's degree

Jörg Hartig was born in Bonn, Germany, in 1974 where he graduated in chemistry and obtained his $\mathrm{PhD}$ in 2003. After a twoyears stay at the Department of Chemistry at Stanford University he moved to the in Life Science, working on the development of switchable DNA three-way junctions. Currently, she is working on her $\mathrm{PhD}$ under the guidance of Jörg Hartig focusing on the field of nu-

University of Konstanz, Germany, to become a Lichtenberg Professor funded by the VolkswagenStiftung. The Hartig group is interested in the development of RNA-based switches of gene expression, the role of cleic acid nanodevices. She is interested in the develop ment of addressable DNA nanostructures and novel nucleic acid hybrid materials.

unusual nucleic acid structures such as quadruplexes in genetic processes, and in nucleic acids as versatile building blocks for nanoarchitectures. 


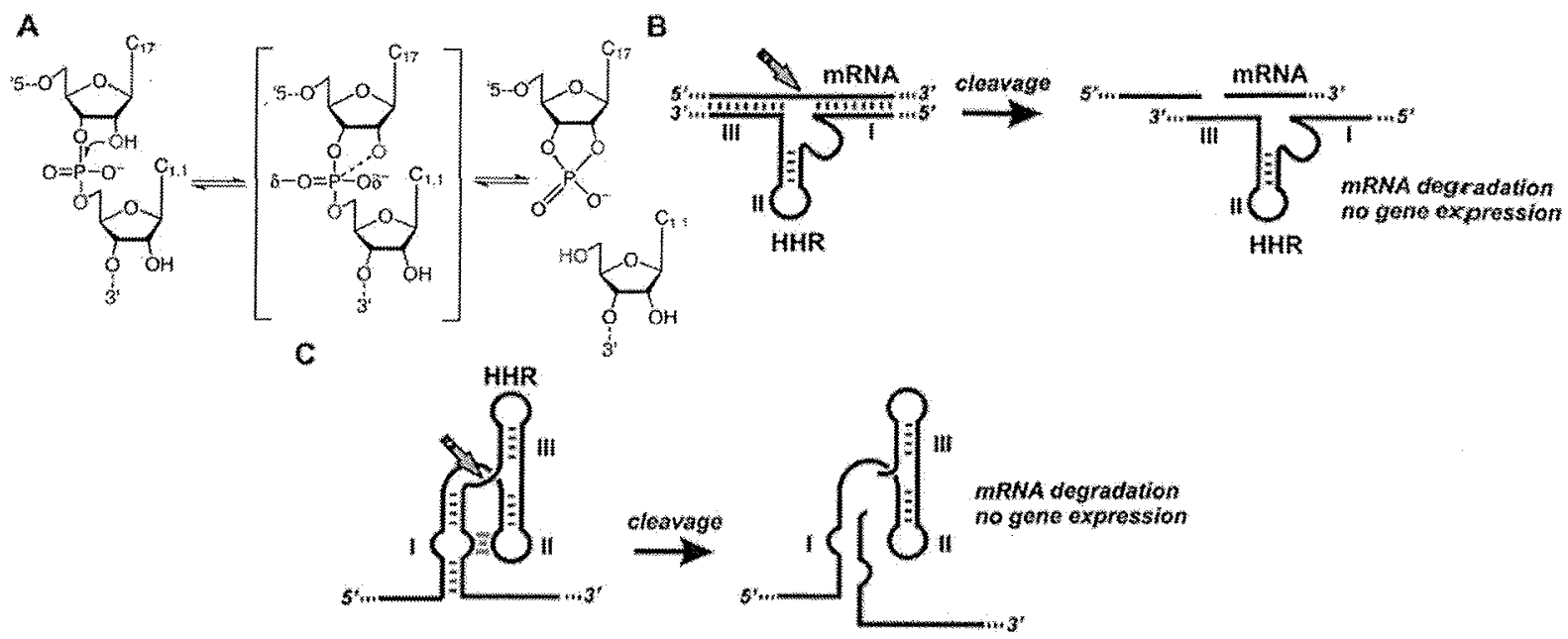

Scheme 1 The hammerhead ribozyme (HHR) for regulation of mRNA integrity. A: Phosphodiester cleavage mechanism of the HHR. B: Regulation of gene expression by intermolecular (in trans) cleavage of an mRNA. The HHR anneals to the target mRNA, thereby forming the active cleavage site. Cleavage of the HHR (indicated by the grey arrow) results in mRNA degradation and gene expression is turned off. C: Regulation of gene expression by intramolecular (in cis) cleavage of the HHR. The self-cleaving HHR is introduced into the target mRNA. Upon HHR cleavage, mRNA is degraded and gene expression is inhibited.

\section{Ribozymes as Parts for Artificial mRNA Switches}

Phosphodiester-cleaving ribozymes such as the HHR are capable of targeting RNA by intermolecular (in trans) cleavage, if divided into a catalytic and a substrate strand (see Scheme 1, B). ${ }^{25}$ This approach of utilizing ribozymes for targeting endogenous mRNA in trans in order to specifically control gene expression ${ }^{26}$ has been developed in the 1990 s but has received a setback with the discovery of RNA interference (see below for detailed description) which since then became the most frequently used strategy for exogenous control of gene expression. On the other hand, in order to control transgenes, artificial control units that allow the regulation of gene expression can be inserted into the genetic information. For this purpose, self cleaving ribozymes have been introduced into mRNA in order to control the mRNA integrity. Pioneering work for the in cis control of gene expression via ribozymes was carried out by Mulligan and co-workers with the insertion of a full-length HHR into the mRNA of a eukaryotic reporter gene (see Scheme 1, C). ${ }^{27}$ In eukaryotic cells, the stability of the mRNA depends on the presence of a $5^{\prime}$-cap and a 3'-poly(A) tail. By removing cap or tail, the ribozyme-mediated self-cleavage results in mRNA destabilization and hence reduced gene expression. ${ }^{27}$ Interestingly, efficient down-regulation of gene expression was only observed when the ribozyme was inserted in the $5^{\prime}$-UTR, whereas insertion in the $3^{\prime}$-UTR or in intronic regions did not result in effective inhibition of gene expression. Although the introduced ribozymes lacked an aptamer domain and hence the possibility to control ribozyme activity with a specific ligand, it was possible to turn them into artificial riboswitches by screening for efficient ribozyme inhibitors in vivo. The most potent inhib- itor turned out to be an adenosine analogue that is randomly incorporated into cellular RNA, thereby inactivating the ribozyme. ${ }^{28}$ Surprisingly, the modified mRNA then still served as an efficient template in translation. Although the high concentration of the nucleoside analogues should lead to toxic effects, the approach was successfully demonstrated in mice. However, more specific ribozymemediated control can be achieved rendering the ribozyme reaction ligand-dependent by engineering allosteric ribozymes. The creation of allosteric ribozymes by attaching aptamer domains to ribozymes enables the specific control of its catalytic activity in a ligand-dependent way. Several examples of ligand-dependent synthetic aptazymes have been realized in the last years. ${ }^{29}$

In order to utilize ribozymes for the conditional control of gene expression, aptazymes were introduced in mRNA of Saccharomyces cerevisiae by Win and Smolke. Aptazymes responsive to theophylline and tetracycline were inserted in the $3^{\prime}$-UTR of a yeast reporter gene. ${ }^{30}$ They realized two different systems, once gene expression is turned on upon ligand addition and once gene expression shuts down (see Scheme 2, A and B). In those designs the aptamers were attached to stem II of a fastcleaving HHR, presumably controlling the formation of the stem I-stem II interactions that are necessary for fast cleavage kinetics. In addition, Smolke and co-workers were able to transfer the principle to mammalian cells. They showed that human T-cell proliferation can be mediated by inserting multiple copies of the ribozymes in the $3^{\prime}$-UTR of a IL-2 fusion transgene. ${ }^{31}$ The insertion of several switches seems necessary since most of the developed RNA switches only show moderate switching ratios.

Although Smolke and 'co-workers described liganddependent control of gene expression utilizing the hammerhead ribozyme, additional measures are needed in 
A

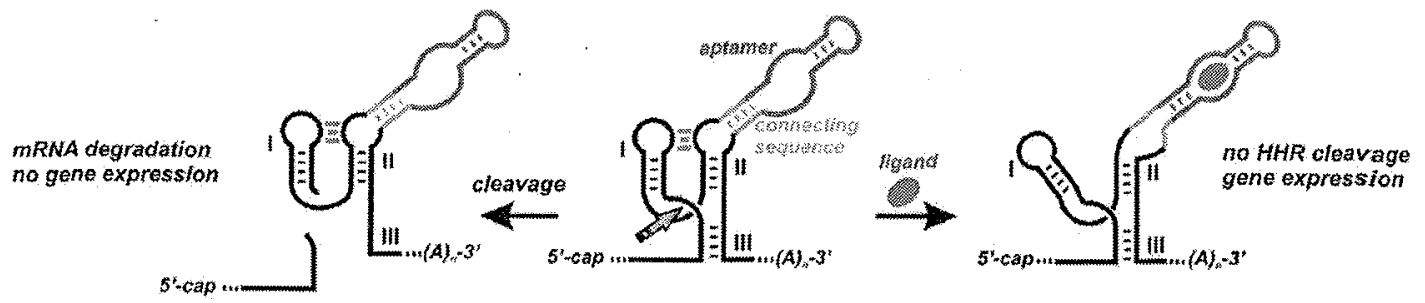

B
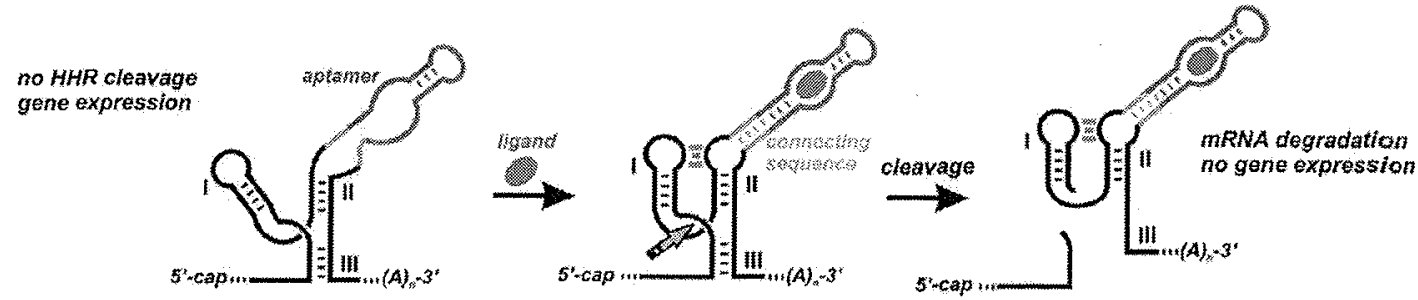

Scheme 2 Eukaryotic RNA parts comprising the HHR aptazyme. A ligand-binding aptamer (red) is attached to stem II of the HHR via a connecting sequence (green). Ligand binding either enables or inhibits ribozyme self-cleavage. The cleavage site is indicated by an arrow. A: Onswitch. Upon ligand binding. HHR cleavage is inhibited and gene expression can proceed. B: Off-switch. Ligand binding enables HHR cleavage and mRNA degradation. Gene expression is inhibited.

order to establish a route to switches with even better performances. In an attempt to combine the power of in vitro selection with the generation of in vivo switches, fastcleaving ligand-dependent ribozymes were generated in the test tube by Breaker, Mulligan, and co-workers followed by insertion into an mRNA. ${ }^{29 \mathrm{~d}}$ Although many fastcleaving, ligand-dependent ribozymes were obtained by this strategy, none of the aptazymes showed pronounced switching behavior when tested in the mRNA context. Possible reasons could be problems of ribozyme folding in vivo or the cleavage kinetics of the selected ribozymes being unsuited for efficient regulation of mRNA stability.

Our group was initially interested in the development of efficient artificial RNA switches in bacteria. We as well chose the hammerhead ribozyme as expression platform in such switches since RNA cleavage has the potential to serve as regulatory mechanism in many organisms and in RNA classes other than mRNA. In contrast to eukaryotic cells, bacterial mRNA stability is not mediated by the presence of a $5^{\prime}$-cap structure. Therefore messages that are cleaved in the $5^{\prime}$-UTR can still be translated efficiently in E. coli. In order to develop a HHR ribozyme-based switch of gene expression that operates in prokaryotic cells we aimed at controlling translation initiation. ${ }^{6 c}$ In bacteria an accessible, single-stranded Shine-Dalgarno (SD) sequence within the ribosome binding site (RBS) in the mRNA is essential for an efficient translational initiation. ${ }^{32}$ Ligand-dependent masking of the SD sequence is a common mechanism in naturally occurring riboswitches.' In our design, we incorporated the RBS into an extended stem I in the HHR fold. Upon autocatalytic mRNA cleavage, the RBS gets liberated and translation can proceed. By incorporation of a theophylline aptamer in stem III of the HHR and in vivo optimization of the connecting sequence, we identified a theophylline-dependent aptazyme in which the tertiary contacts, necessary for core stabilization and fast cleavage kinetics, can be maintained (see Scheme 3, A). .c $^{\circ}$
In order to identify suited sequences that show sufficient switching performances optimization of defined elements of the aptazymes is necessary. As demonstrated early by Breaker and co-workers, the sequences connecting the aptamer and ribozyme are crucial for the switching of ribozyme activity upon ligand binding since this site communicates the binding event to the catalytic core of the ribozyme. ${ }^{29 \mathrm{a}}$ In order to identify such optimized sequences we applied a technique based on the in vivo screening of mutant pools that contain randomized sequences at the connection site between ribozyme and aptamer. Our studies demonstrated the importance of fine-tuning the connecting sequence of aptamer and ribozyme. In earlier studies the connecting sequence was often generated by randomizing responsible nucleotides and in vitro selection protocols. ${ }^{29 a}$ However, we screened an optimized connecting sequence for the aptazyme approach described above in vivo, ensuring that all selected clones can be used as RNA switches in prokaryotic cells. ${ }^{33}$ In addition to our studies Ellington and co-workers described a combined in vitro-in vivo selection protocol, which is characterized by a higher throughput than in vivo screening methods. ${ }^{34}$

Further studies have demonstrated that in principle the hammerhead aptazyme can be designed by attachment of the aptamer to each of the three stems. ${ }^{6 a, c, 30,35}$ In addition, a ligand-dependent ribozyme system in bacteria was developed by Maeda and co-workers. ${ }^{36}$ They incorporated the RBS in stem III of a theophylline-dependent HHR, lacking the tertiary interactions between stem I and II. Therefore special $E$. coli growth conditions with high magnesium ion concentrations were needed. ${ }^{37}$ However, our group was wondering whether it is possible to further expand the HHR scaffold in order to find other positions for the introduction of an aptamer. Such a design is interesting in the following aspects: If more than one aptamer can be connected to a given ribozyme, two and more input switches can be designed utilizing the hammerhead motif. ${ }^{35,38}$ More important, the following design will allow 
the ligand-dependent in trans-targeting of mRNA since restrictions due to stem $\mathrm{I}-\mathrm{II}$ interactions are not applying to the substrate (mRNA) strand. We decided to introduce an additional stem (termed stem IV) to stem I of the HHR, thereby creating an artificial three-way junction. The specific design of the junction point containing unpaired nucleotides was crucial for in vivo activity and liganddependent control of the HHR.

We identified a powerful theophylline-dependent artificial switch of gene expression based on the enlarged HHR scaffold (see Scheme 3, C). ${ }^{6 \mathrm{~b}}$ More than 100 -fold induction of gene expression with very little background expression in the off-state was observed. ${ }^{6 b}$

So far, aptazyme-based control of gene expression has only been achieved in bacteria with the model ligand theo- phylline. ${ }^{6 c, 37,39}$ However, the use of theophylline is problematic in vivo, since high concentrations are needed that are already slightly toxic. ${ }^{40}$ In order to explore additional compounds as triggers of gene expression we tested whether natural aptamer motifs occurring in bacterial riboswitches can be utilized in a ribozyme-dependent way. We chose an aptamer sequence that senses the ligand thiamine pyrophosphate (TPP). TPP riboswitches are the most widespread RNA switches found to date with many examples in bacteria, ${ }^{41}$ plants, ${ }^{42}$ and fungi. ${ }^{43}$ We connected a TPP aptamer to our HHR setup, thereby creating efficient ligand-dependent switches. ${ }^{6 a}$ After randomizing six nucleotides at the aptamer-ribozyme connection region, we performed an in vivo screen to search for functional RNA switches. With this approach we were able to

A

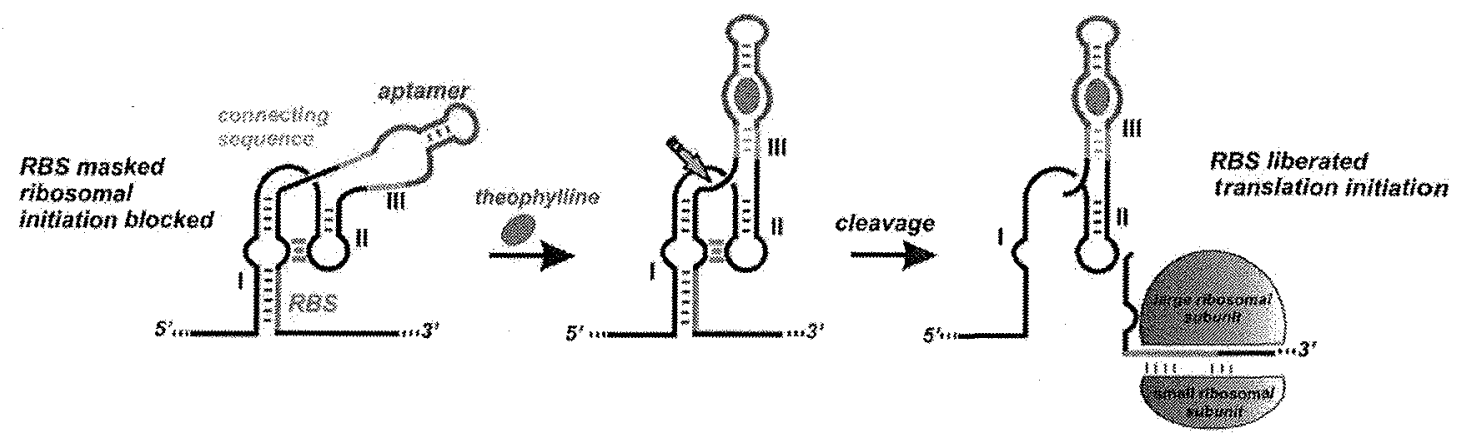

B
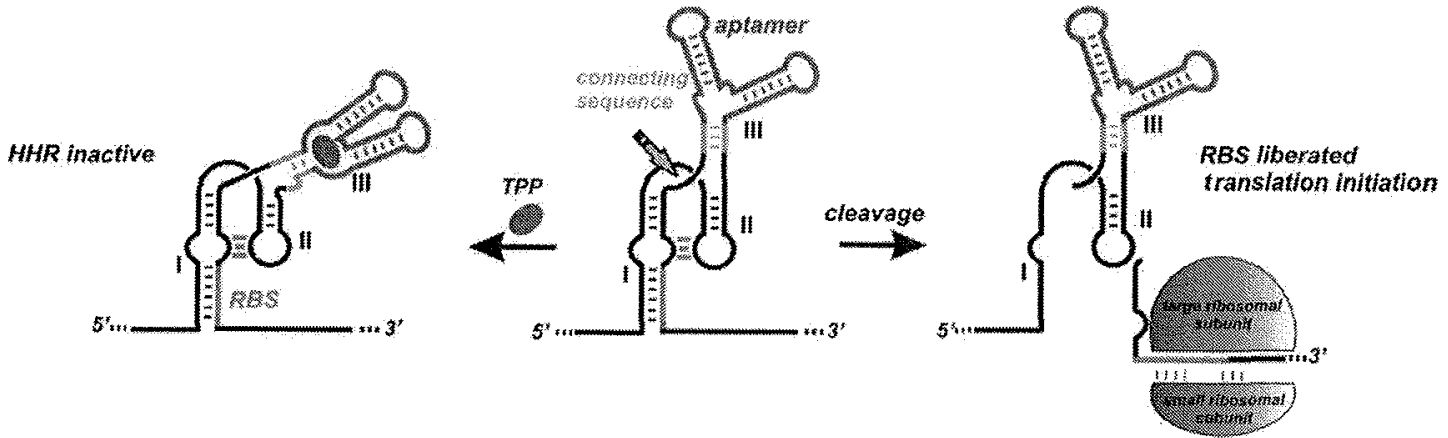

$\mathrm{c}$
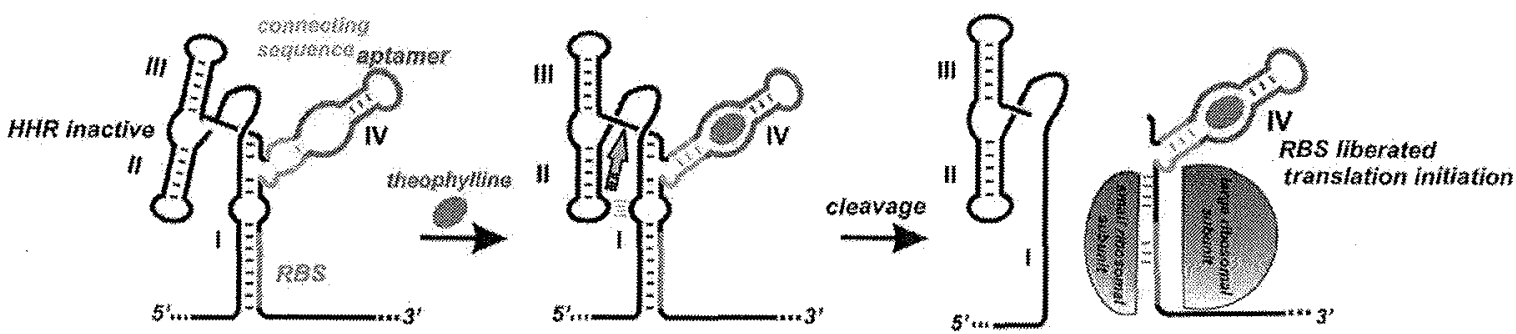

Scheme 3 Bacterial aptazyme switches, regulating translational initiation. A: The ribosome binding site (RBS, orange) is incorporated into stem I of the HHR and therefore not accessible for the ribosome. The theophylline-binding aptamer (red) is attached to stem III of the HHR Interaction with theophylline activates the HHR and cleaves the mRNA. As a result, the RBS gets liberated and translation is initiated. B: Artificial regulation of gene expression by introduction of the TPP aptamer (red) in stem II. Binding of TPP deactivates HHR self-cleavage and inhibits gene expression. If no TPP is bound the RBS (orange) is liberated and gene expression can proceed. C: Design of an expanded HHR format comprising a three-way junction. The theophylline aptamer (red) is incorporated into a newly added stem IV. This enlarged scaffold is as well capable of controlling gene expression via external addition of theophylline, ribozyme activation, and freeing of the RBS. 
identify both artificial switches that get inhibited and activated by the addition of thiamine (see Scheme $3, \mathbf{B}$ ). ${ }^{6 \mathrm{a}}$ Gene expression is switched upon the external addition of thiamine. Thiamine is processed via thiamine kinase and thiamine phosphate kinase to yield TPP, ${ }^{44}$ which is then sensed by the aptazyme. Interestingly, these switches are operating in bacteria that possess a functional TPP biosynthesis pathway. Hence, it seems possible to utilize natural metabolites in artificial switches of gene expression. In addition, with this design we demonstrated that the developed platform based on the HHR is modular with respect to the attachment of different aptamer sequence hand hence ligand reprogramming.

Next we demonstrated that the cleavage-based mechanism is indeed universal with respect to the application in different organisms. For this purpose we transferred the theophylline-dependent aptazyme described above from bacteria $^{6 c}$ (see Scheme 3, A) to mammalian cell cultures. When inserted into a 5'-UTR of a mammalian mRNA, the same sequences developed in bacteria showed regulation of gene expression upon addition of theophylline. Since ribozyme cleavage of the respective $m$ RNA detaches the stabilizing cap structure from the mRNA, the remaining cleavage product gets degraded rapidly. Hence, upon triggering of ribozyme cleavage with theophylline, gene expression is turned off opposed to the observed on-switch in the bacterial system. ${ }^{45}$ In addition we optimized the performance of the eukaryotic switches by removing artificial start codons as well as re-screening of the connecting sequence, resulting in sixfold switches of gene expression in HEK and HeLa cell lines. ${ }^{45}$ Importantly, these systems for conditional gene expression do not require additional regulatory protein factors compared to the frequently used tetracycline systems. ${ }^{46}$

\section{Regulation of Further RNA Classes}

Having created different ligand-dependent aptazyme designs in the context of the bacterial mRNA, we wondered whether the usage of self-cleaving ribozymes is more generally applicable with respect to other RNA classes. As mentioned in the introduction other RNA involved in gene expression are tRNA and rRNA, on which we focused in our recent studies.

In order to regulate tRNA we further developed a system based on an in vitro translation system for the label-free detection of theophylline developed by Ogawa and Maeda. ${ }^{47}$ We attached a theophylline-dependent ribozyme to the 5 '-end of an $E$. coli tRNA, aiming at activation of the tRNA for translation by ligand addition (see Scheme 4, A). We used a mutated $\mathrm{RNA}^{\mathrm{Ser}}{ }_{\text {CuA }}$, recognizing the amber stop codon. Ribozyme-mediated activation of the tRNA ${ }_{\text {CUA }}^{\text {Ser }}$ suppresses termination and instead decodes the mRNA by incorporating serine, resulting in eGFP expression. Therefore in our design a gain of function occurs when the ribozyme cleavage reaction takes place. We achieved this by attaching of the ribozyme to the tRNA in a way that the formation of the typical cloverleaf structure of the tRNA is disturbed but gets liberated to form an active tRNA upon ribozyme cleavage (see Scheme 4, A) ${ }^{48}$ With this technology it should be possible to specifically switch the incorporation of genetically encoded, unnatural amino acids, triggered via small-molecule dependent ribozymes. In addition, our approach should allow for the post-transcriptional control of amino acid identity in proteins by combining two or more switches. Moreover the presented mechanism should be transferable to other organisms, as the structural features of the general tRNA pathway are conserved throughout all kingdoms of life. ${ }^{49}$

In another approach we controlled the integrity of the $16 \mathrm{~S}$ rRNA of E. coli. ${ }^{50}$ The 16S rRNA together with several proteins constitutes the small ribosomal subunit in bacteria. ${ }^{51}$ In our design we triggered the cleavage of the $16 \mathrm{~S}$ rRNA by insertion of a TPP-dependent HHR (see Scheme 4, B). Interestingly, at certain positions the insertion of the large HHR sequence into the 16S rRNA did not affect its activity; whereas HHR-induced cleavage is not tolerated and results in loss of 16S rRNA activity. In its inactive form the TPP aptazyme is not interfering with translation. Upon thiamine addition, the HHR is activated and cleaves the $16 \mathrm{~S}$ rRNA, which is then degraded. The successfully engineered, artificial ribosomes can be switched on or off specifically via the addition of a small molecule. ${ }^{50}$ The developed system could prove useful as a tool in order to understand ribosome folding and assembly.

In our designs gene expression was mediated by directly influencing mRNA stability or the mechanism of translation via tRNA or rRNA integrity. In addition mRNA stability in eukaryotes can be affected indirectly through an alternative pathway, called RNA interference (RNAi). By this mechanism a specific gene is knocked down via a small interfering RNA (siRNA) sequence that is complementary to the targeted mRNA. ${ }^{52}$ During RNAi a doublestranded RNA or a short hairpin RNA (shRNA) is processed by Dicer and the RNA-induced silencing complex (RISC) into an siRNA. MicroRNA (miRNA) are genetically encoded and processed by a similar mechanism. The primary microRNA (pri-miRNA) is a shRNA with singlestranded $3^{\prime}$ - and $5^{\prime}$-overhangs that are processed by the endonuclease drosha to the precursor miRNA (premiRNA). ${ }^{53}$ This pre-miRNA serves as a substrate for Dicer, gets processed, and then results in specific gene knockdown.

RNAi is a highly important mechanism in natural gene regulation, but has also been used for constructing artificial ligand-dependent controls of gene expression. ${ }^{54}$ Integration of a theophylline aptamer into an shRNA resulted in ligand-dependent RNAi activity. ${ }^{55}$ Recently, Yokobayashi and co-workers demonstrated activation of RNAi by rendering a pri-miRNA dependent on aptazyme cleavage. ${ }^{56}$ The used RNA transcript comprised a structural analogue of a pri-miRNA, connected with an allosteric HHR comprising the theophylline aptamer. In addition, an 
inhibitory strand was incorporated that hybridizes with the $5^{\prime}$-end of the pri-miRNA and can only be liberated by ribozyme cleavage upon theophylline addition. Exposure of the $5^{\prime}$-single-stranded region enables processing by drosha and activation of RNAi (see Scheme 4, C). Inter- estingly, the theophylline-dependent aptazyme used by Yokobayashi and co-workers was initially developed in bacteria by our group, ${ }^{6 c}$ again showing a high interspecies compatibility of HHR-based regulatory mechanisms.

A

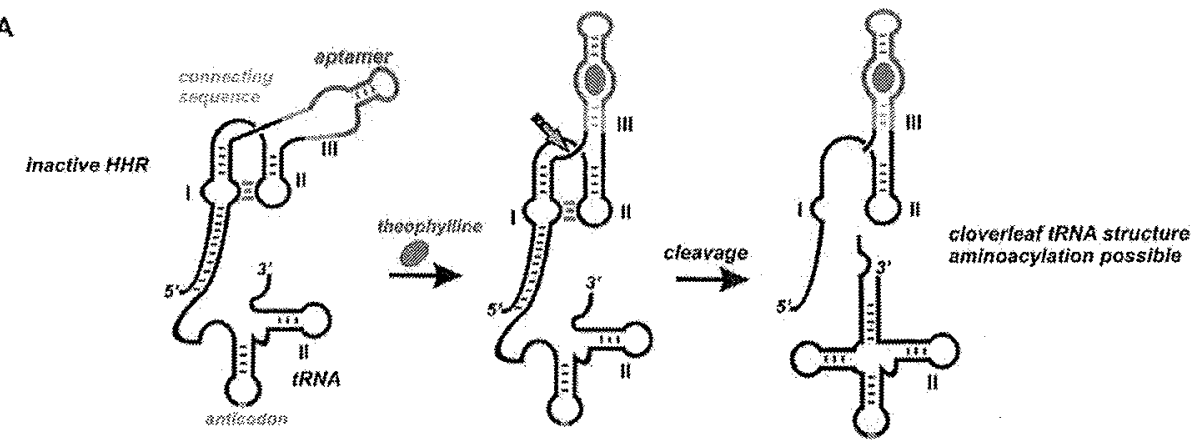

B
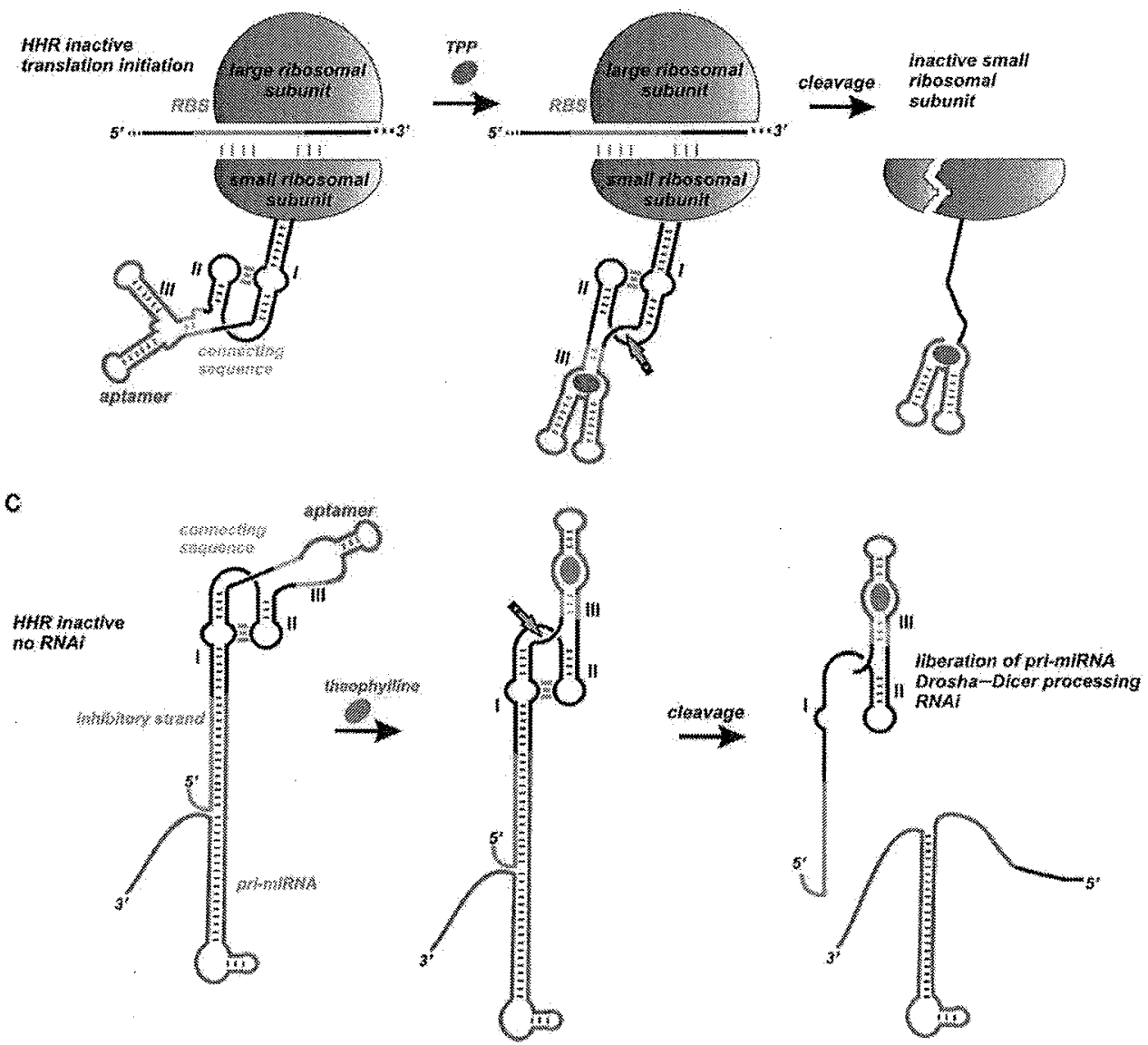

Scheme 4 Ribozyme-based regulation of different RNA classes. A: Small-molecule-dependent regulation of tRNA function in $E$.coli. The theophylline-dependent aptazyme (see Scheme $2, \mathbf{A}$ ) is connected to an amber suppressor tRNA ${ }^{\text {Ser }}$ CuA. This attachment disrupts the typical tRNA cloverleaf structure and thereby inhibits tRNA function. Interaction with theophylline leads to ribozyme cleavage and liberation of a functional tRNA that acts in translation. B: Aptazyme-mediated regulation of 16S-rRNA in E. coli. Incorporation of the inactive TPP-aptazyme into 16S-rRNA does not interfere with translation and enables gene expression. Ribozyme activation via addition of TPP results in cleavage of the 16S rRNA and inhibition of the small ribosomal subunit. C: Ligand-dependent regulation of RNA interference (RNAi) via an aptazyme in eukaryotic cells. The $5^{\prime}$ end of a pri-miRNA analogue is attached to the theophylline-regulated HHR aptazyme. An inhibitory strand (orange) connected to the HHR is complementary to the single-stranded 5'-region of the pri-miRNA necessary for processing and RNAi activity. Theophylline addition activates the HHR and cleavage yields the pri-miRNA analogue that can be processed and knockdown of gene expression via RNAi occurs. 


\section{$5 \quad$ Conclusion}

RNA switches are able to regulate prokaryotic and eukaryotic gene expression in a ligand-dependent manner. Especially ribozyme-based mechanisms show high potentials to act in many different contexts, as their RNA cleavage results in irreversible changes. As described above, our group has shown that the HHR is a very versatile and powerful tool to regulate gene expression in $E$. coli. ${ }^{6,48,50}$ We showed that the developed RNA parts can regulate mRNA accessibility, but are also highly transferable to other RNA classes (rRNA, tRNA). ${ }^{48,50}$ The group of Yokobayashi even showed that HHR self-cleavage is capable of regulating RNAi substrates. ${ }^{56}$ All these RNA parts exhibit a highly modular nature, which should simply allow for the exchange of one ligand-binding aptamer to another. However, many aptazyme switches reported by different groups described here have been shown to work only with a limited number of aptamers. Theophylline has been employed frequently, and antibiotics have been used in yeast. We were able to integrate an aptazyme responding to thiamine in $\mathrm{mRNA}^{6 \mathrm{a}}$ as well as in tRNA. ${ }^{48}$ In order to apply these principles to conditional gene expression in the life sciences, there is an increasing need for additional ligands that are nontoxic, penetrate cellular membranes, and are not metabolized by the targeted cells. Ligand-dependent RNA switches are interesting alternatives to protein-based switches that are utilized in the life sciences so far. In addition, due to their modular nature they offer high potentials in the emerging field of synthetic biology for re-programming cellular circuits and functions.

\section{Acknowledgment}

J.S.H. acknowledges the VolkswagenStiftung for funding a Lichtenberg Professorship. We thank the members of the Hartig group for support.

\section{References}

(1) Winkler, W.; Nahvi, A.; Breaker, R. R. Nature (London) 2002, 419, 952 .

(2) (a) Barrick, J. E.; Corbino, K. A.; Winkler, W. C.; Nahvi, A.; Mandal, M.; Collins, J.; Lee, M.; Roth, A.; Sudarsan, N.; Jona, I.; Wickiser, J. K.; Breaker, R. R. Proc. Natl. Acad. Sci. U.S.A. 2004, 101, 6421. (b) Winkler, W. C.; Breaker, R. R. Annu. Rev. Microbiol. 2005, 59, 487. (c) Schwalbe, H.; Buck, J.; Furtig, B.; Noeske, J.; Wohnert, J. Angew. Chem. Int. Ed. 2007, 46, 1212.

(3) Werstuck, G.; Green, M. R. Science 1998, 282, 296.

(4) (a) Tuerk, C.; Gold, L. Science 1990, 249, 505. (b) Ellington, A. D.; Szostak, J. W. Nature (London) 1990 , 346, 818. (c) Klug, S. J.; Famulok, M. Mol. Biol. Rep. 1994, $20,97$.

(5) Wieland, M.; Hartig, J. S. Nat. Protoc. 2009, 4, 1632.

(6) (a) Wieland, M.; Benz, A.; Klauser, B.; Hartig, J. S. Angew. Chem. Int. Ed. 2009, 48, 2715. (b) Wieland, M.; Gfell, M.; Hartig, J. S. RNA 2009, 15, 968. (c) Wieland, M.; Hartig, J. S. Angew. Chem. Int. Ed. 2008, 47, 2604.

(7) Guerrier-Takada, C.; Altman, S. Science 1984, 223, 285.

(8) Bass, B. L.; Cech, T. R. Nature (London) 1984, 308, 820.
(9) Nissen, P.; Hansen, J.; Ban, N.; Moore, P. B.; Steitz, T. A. Science 2000, 289, 920.

(10) (a) Winkler, W. C.; Nahvi, A.; Roth, A.; Collins, J. A.; Breaker, R. R. Nature (London) 2004, 428, 281.

(b) Collins, J. A.; Imov, I.; Baker, S.; Winkler, W. C. Genes Dev. 2007, 21, 3356.

(11) Lee, E. R.; Baker, J. L.; Weinberg, Z.; Sudarsan, N.; Breaker, R. R. Science 2010, 329, 845 .

(12) (a) Stahley, M. R.; Strobel, S. A. Curr. Opin. Struct. Biol. 2006, 16, 319. (b) Adams, P. L.; Stahley, M. R.; Kosek, A. B.; Wang, J.; Strobel, S. A. Nature (London) 2004, 430, 45.

(13) Thompson, K. M.; Syrett, H. A.; Knudsen, S. M.; Ellington, A. D. BMC Biotechnology 2002, 2, 21 .

(14) Fedor, M. J. Annu. Rev. Biophys. 2009, 38, 271.

(15) Blount, K. F.; Uhlenbeck, O. C. Biochem. Soc. Trans. 2002, $30,1119$.

(16) Seehafer, C.; Kalweit, A.; Steger, G.; Graf, S.; Hammann, C. RNA 2011, 17, 21.

(17) (a) Canny, M. D.; Jucker, F. M.; Kellogg, E.; Khvorova, A.; Jayasena, S. D.; Pardi, A. J. Am. Chem. Soc. 2004, 126 , 10848. (b) Khvorova, A.; Lescoute, A.; Westhof, E.; Jayasena, S. D. Nat. Struct. Biol. 2003, 10, 708. (c) Martick, M.; Scott, W. G. Cell 2006, 126, 309.

(18) Martick, M.; Lee, T. S.; York, D. M.; Scott, W. G. Chem. Biol. 2008, 15, 332.

(19) Bartel, D. P.; Unrau, P. J. Trends Cell Biol. 1999, 9, M9.

(20) Ekland, E. H.; Szostak, J. W.; Bartel, D. P. Science 1995, $269,364$.

(21) (a) Zhang, B.; Cech, T. R. Chem. Biol. 1998, 5, 539.

(b) Zhang, B.; Cech, T. R. Nature (London) 1997, 390, 96.

(22) (a) Lohse, P. A.; Szostak, J. W. Nature (London) 1996, 381 , 442. (b) Illangasekare, M.; Sanchez, G.; Nickles, T.; Yarus, M. Science 1995, 267, 643. (c) Jenne, A.; Famulok, M. Chem. Biol. 1998, 5, 23.

(23) Lorsch, J. R.; Szostak, J. W. Nature (London) 1994, 371, 31.

(24) (a) Seelig, B.; Jaschke, A. Chem. Biol. 1999, 6, 167. (b) Serganov, A.; Keiper, S.; Malinina, L.; Tereshko, V.; Skripkin, E.; Hobartner, C.; Polonskaia, A.; Phan, A. T.; Wombacher, R.; Micura, R.; Dauter, Z.; Jaschke, A.; Patel, D. J. Nat. Struct. Mol. Biol. 2005, 12, 218.

(25) Uhlenbeck, O. C. Nature (London) 1987, 328, 596.

(26) (a) Vaish, N. K.; Kore, A. R.; Eckstein, F. Nucleic Acids Res. 1998, 26, 5237. (b) Bramlage, B.; Luzi, E.; Eckstein, F. Trends Biotechnol. 1998, 16, 434.

(27) Yen, L.; Svendsen, J.; Lee, J. S.; Gray, J. T.; Magnier, M.; Baba, T.; D'Amato, R. J.; Mulligan, R. C. Nature (London) 2004, 431, 471 .

(28) Yen, L.; Magnier, M.; Weissleder, R.; Stockwell, B. R.; Mulligan, R. C. RNA 2006, 12, 797.

(29) (a) Soukup, G. A.; Breaker, R. R. Proc. Natl. Acad. Sci. U.S.A. 1999, 96, 3584. (b) Piganeau, N.; Jenne, A.; Thuillier, V.; Famulok, M. Angew. Chem. Int. Ed. 2001, 40, 3503. (c) Hartig, J. S.; Najafi-Shoushtari, S. H.; Grune, I.; Yan, A.; Ellington, A. D.; Famulok, M. . (d) Link, K. H.; Guo, L.; Ames, T. D.; Yen, L.; Mulligan, R. C.; Breaker, R. R. Biol. Chem. 2007, $388,779$.

(30) Win, M. N.; Smolke, C. D. Proc. Natl. Acad. Sci. U.S.A. 2007, 104, 14283.

(3I) Chen, Y. Y.; Jensen, M. C.; Smolke, C. D. Proc. Natl. Acad. Sci. U.S.A. 2010, 107, 8531.

(32) Schlax, P. J.; Worhunsky, D. J. Mol. Microbiol. 2003, 48, 1157.

(33) Wieland, M.; Hartig, J. S. ChemBioChem 2008, 9, 1873.

(34) Chen, X.; Denison, L.; Levy, M.; Ellington, A. D. RNA 2009, 15, 2035.

(35) Win, M. N.; Smolke, C. D. Science 2008, 322, 456. 
(36) (a) Ogawa, A.; Maeda, M. Nucleic Acids Symp. Ser. 2007, 389. (b) Ogawa, A.; Maeda, M. Bioorg. Med. Chem. Lett. 2007, 17, 3156

(37) Ogawa, A.; Maeda, M. ChemBioChem 2008, 9, 206.

(38) (a) Penchovsky, R.; Breaker, R. R. Nat. Biotechnol. 2005, 23, 1424. (b) Jose, A. M.; Soukup, G. A.; Breaker, R. R. Nucleic Acids Res. 2001, 29, 1631.

(39) (a) Suess, B.; Fink, B.; Berens, C.; Stentz, R.; Hillen, W. Nucleic Acids Res. 2004, 32, 1610. (b) Lynch, S. A.; Desai S. K.; Sajja, H. K.; Gallivan, J. P. Chem. Biol. 2007, 14, 173.

(40) Topp, S.; Gallivan, J. P. J. Am. Chem. Soc. 2007, 129, 6807.

(41) (a) Kazanov, M. D.; Vitreschak, A. G.; Gelfand, M. S. BMC Genomics 2007, 8, 347. (b) Rentmeister, A.; Mayer, G.; Kuhn, N.; Famulok, M. Biol. Chem. 2008, 389, 127.

(42) Wachter, A.; Tunc-Ozdemir, M.; Grove, B. C.; Green, P. J.; Shintani, D. K.; Breaker, R. R. Plant Cell 2007, 19, 3437.

(43) Cheah, M. T.; Wachter, A.; Sudarsan, N.; Breaker, R. R. Nature (London) 2007, 447, 497

(44) Settembre, E.; Begley, T.P.; Ealick, S. E. Curr. Opin. Struct. Biol. 2003, 13, 739 .

(45) Auslander, S.; Ketzer, P.; Hartig, J. S. Mol. Biosyst. 2010, 6, 807.
(46) Berens, C.; Hillen, W. Eur. J. Biochem. 2003, $270,3109$.

(47) Ogawa, A.; Maeda, M. ChemBioChem 2008, 9, 2204

(48) Berschneider, B.; Wieland, M.; Rubini, M.; Hartig, J. S. Angew. Chem. Int. Ed. 2009, 48, 7564.

(49) Hopper, A. K.; Phizicky, E. M. Genes Dev. 2003, 17, 162.

(50) Wieland, M.; Berschneider, B.; Erlacher, M. D.; Hartig, J.S. Chem. Biol. 2010, 17, 236.

(51) (a) Schluenzen, F.; Tocilj, A.; Zarivach, R.; Harms, J.; Gluehmann, M.; Janell, D.; Bashan, A.; Bartels, H.; Agmon, I.; Franceschi, F.; Yonath, A. Cell 2000, 102, 615.

(b) Wimberly, B. T.; Brodersen, D. E.; Clemons, W. M. Jr.; Morgan-Warren, R. J.; Carter, A. P.; Vonrhein, C.; Hartsch, T.; Ramakrishnan, V. Nature (London) 2000, 407, 327.

(52) Mello, C. C.; Conte, D. Jr. Nature (London) 2004, 431, 338

(53) Zeng, Y.; Cullen, B. R. J. Biol. Chem. 2005, 280, 27595.

(54) Dorsett, Y.; Tuschl, T. Nat. Rev. Drug Discov. 2004, 3, 318.

(55) (a) An, C. I.; Trinh, V. B.; Yokobayashi, Y. RNA 2006, 12, 710. (b) Tuleuova, N.; An, C. I.; Ramanculov, E.; Revzin, A.; Yokobayashi, Y. Biochem. Biophys. Res. Commun. 2008, 376, 169 .

(56) Kumar, D.; An, C. I.; Yokobayashi, Y.J. Am. Chem. Soc. $2009,131,13906$. 